\title{
Multiple Recurrences of Cardiac Myxomas with Acute Tumoral Pulmonary Embolism
}

\author{
Waldomiro Manfroi, Silvia R. R. Vieira, Eduardo K. Saadi, Jair Saadi, Carolina Alboim \\ Porto Alegre, RS - Brazil
}

\begin{abstract}
We report the case of a 42-year-old female with a second recurrence of cardiac myxoma. Her first diagnosis was at the age of 24 years, when cardiac tumors were withdrawn from her right ventricle and left atrium. Her first recurrence was at the age of 36 years, when tumors were removed from the left and right atria, and the right ventricle. Six years later, the patient was admitted to the Hospital das Clínicas de Porto Alegre complaining of sudden dyspnea, dry cough, and pain in the right hypochondrium, which bore no relation to breathing. The transesophageal echocardiography showed a small tumor in the interatrial septum, close to the superior vena cava, and 2 larger tumors in the right ventricle, 1 close to the outflow tract and the other almost completely obstructing the right branch of the pulmonary artery. The patient was referred to surgery, in which myxomas were removed from the right atrium and ventricle with extension to the right pulmonary artery. The postoperative period was uneventful.
\end{abstract}

Cardiac myxomas have an annual incidence estimated in $0.5 / 1,000,000 /$ year $^{1}$. Their prevalence varies from $0.0017 \%$ to $0.28 \%$ of all cardiac disorders ${ }^{2}$. They represent $50 \%$ to $75 \%$ of all primary cardiac tumors ${ }^{3-5}$. Approximately $90 \%$ of these benign tumors occur in the left atrium, from 5\% to $20 \%$ in the right atrium, and from $2 \%$ to $5 \%$ in the right and left ventricles ${ }^{1,3,5-7}$. Biatrial tumors are found in less than $2.5 \%$ of all cases ${ }^{7}$. Approximately $70 \%$ of the affected patients are females, and their age of highest incidence is around 50 years ${ }^{4,6}$.

Recurrence of myxomas has been observed in $3 \%$ to $22 \%$ of patients. The time for these recurrences varies from 3 months to 14 years after the initial resection, and $87 \%$ of

Hospital de Clínicas de Porto Alegre - UFRGS

Mailing address: Waldomiro Manfroi - Hospital de Clínicas de Porto Alegre - Rua Ramiro Barcelos, 2350 - 90035-003 - Porto Alegre, RS, Brazil - E-mail: Manfroi@orion.ufrgs.br

English version by Stela Maris C. e Gandour them occur in 5 years. Repetitive recurrences are rarer $(1.3 \%)$. Asymptomatic recurrences are observed in young patients who have a familial history of tumor or multifocal myxomas.

Myxomas may be asymptomatic (12\%) or have varied manifestations, such as symptoms resulting from mitral valvar heart disease (43\%), systemic embolism (27\%), pulmonary embolism $(25 \%)$, and sudden death $(15 \%)^{4}$.

The best diagnostic method for locating and assessing the extension of myxomas and for detecting their recurrences continues to be echocardiography, which has a sensitivity of up to $100 \%{ }^{7,8}$. However, transthoracic echocardiography may not identify tumors smaller than $5 \mathrm{~mm}$ in diameter; whenever a very small tumor is suspected, transesophageal echocardiography is required ${ }^{5,9}$. In selected cases, other examinations, such as computed tomography and nuclear magnetic resonance, may be necessary.

The objective of this study is to report a rare case of a third occurrence of cardiac myxoma associated with tumoral pulmonary embolism.

\section{Case Report}

We report the case of a female patient, who was hospitalized for the first time at the age of 24 years, in 1980, when a cineangiocardiography was performed and revealed a large defect in right ventricular filling, which suggested a cardiac tumor. The patient underwent surgery and, in addition to a large myxoma in the right ventricle, 2 more smaller tumors were found in the left atrium. The postoperative period was uneventful ${ }^{10,11}$. Six years after this first surgery, an echocardiography identified a recurrent myxoma of $2 \mathrm{~cm}$ in the right ventricle, which progressively increased at a rate of $1 \mathrm{~cm} /$ year.

In 1992, the patient was reoperated upon, and tumors in the superior wall of the right atrium, in the middle $1 / 3$ of the right ventricular septum, and in the left atrium were found. No trans- and postoperative complications occurred ${ }^{2}$.

The patient was maintained on a semestral follow-up 
with echocardiographies until October'97. The results were normal, with no alterations on examination. During this period, she underwent a parallel gynecological and endocrinological investigation, which showed breast nodules with benign characteristics, benign colloid nodules of the thyroid, and bilateral micronodular dysplasia of the adrenal cortex.

In September '98, 1 year after the last echocardiography, the patient was readmitted to the hospital due to sudden dyspnea, unproductive cough, and pain in the right hypochondrium with no relation to breathing. On physical examination, the patient had a systolic murmur of the ejection type $(2+/ 6+)$ in the area of the right ventricle, increased intensity of the $2^{\text {nd }}$ cardiac sound in the pulmonary area, and reduction in the respiratory sound in the inferior $1 / 3$ of the right lung, with crepitant rales. During hospitalization, as the patient evolved with severe respiratory insufficiency, she was transferred to the intensive care unit and placed under mechanical ventilation. The chest computed tomography showed images compatible with pulmonary embolism with an area of infarct in the inferior lobe of the right lung; thrombi were identified inside the right ventricle and in the right pulmonary artery. A transesophageal echocardiography was also performed and revealed a tumor in the interatrial septum, on the right side, close to the superior vena cava, and 2 larger tumors in the right ventricle, 1 close to the outflow tract and the other almost entirely obstructing the right branch of the pulmonary artery.

The patient underwent surgery with extracorporeal circulation and cooling down to $22^{\circ} \mathrm{C}$. Periods of low flow and hypothermal cardioplegia were performed for myocardial protection. At first, the right atrium was opened and a mass weighing $19 \mathrm{~g}$ was removed from it (fig. 1). The right ventricle was incised and more fragments of tumoral tissue, which extended inside the pulmonary artery, were removed (fig. 2). During the periods of low flow, the trunk of the pulmonary artery, which was completely obstructed by the tumor, was opened. The entire pulmonary arterial tree was then cleaned with a technique similar to that used in chronic pulmonary thromboembolectomy (fig. 3). The surgery and

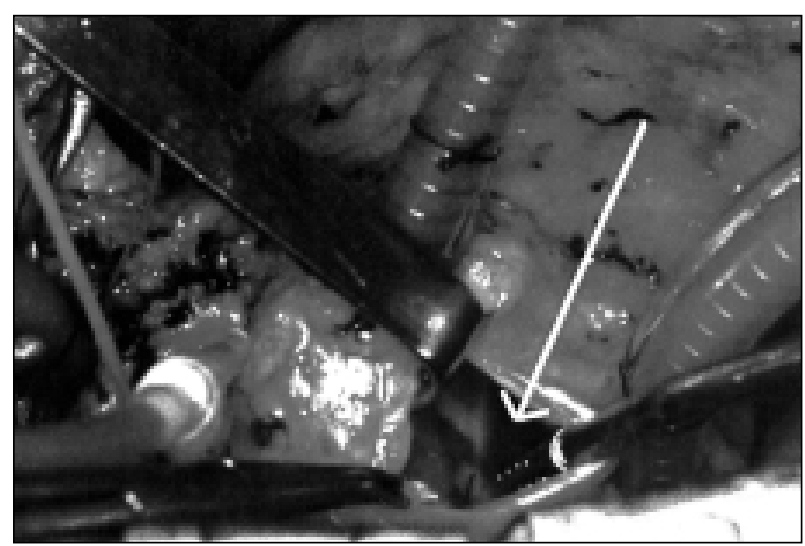

Fig. 1-Myxoma in the right atrium and interatrial septum.

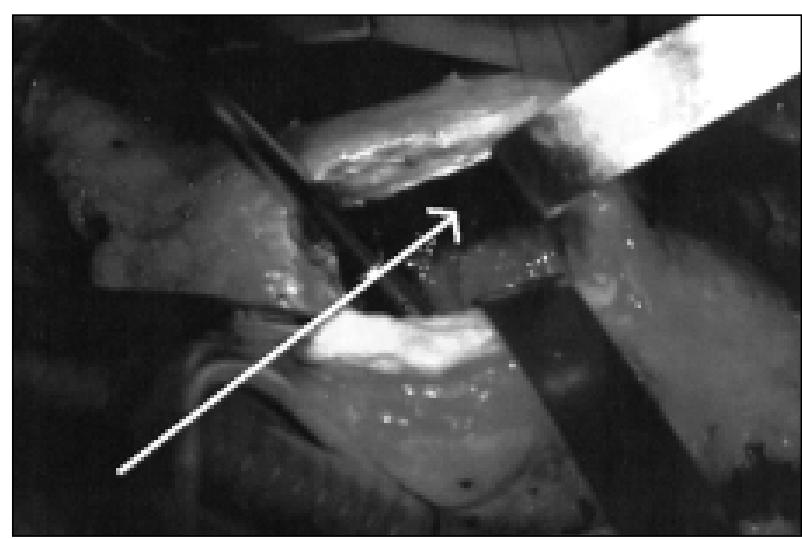

Fig. 2 - Tumor in the right ventricle extending to the outflow tract.

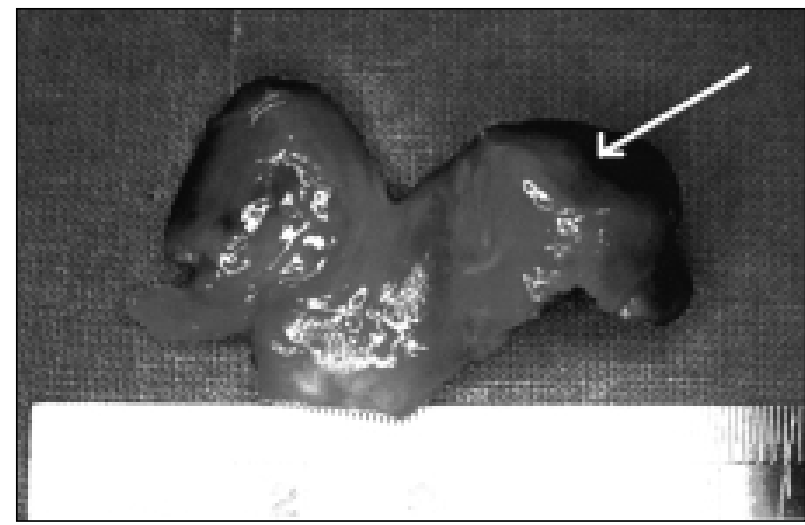

Fig. 3-Myxoma removed from the pulmonary trunk and its branches.

the postoperative period were uneventful. The patient's improvement, from the respiratory point of view, was immediate and drastic. The anatomicopathological diagnosis was myxoma with the presence of fibrin and red thrombi. The patient was discharged from the hospital 1 week after surgery.

\section{Discussion}

Multiple myxomas involving the right cardiac chambers are rare tumors. Pulmonary embolism originating from the tumor mass is a potentially lethal complication. Myxomas have a very low recurrence rate, which usually results from incomplete excision of the tumor, tumor implantation, or a histological misinterpretation of a mesenchymal sarcoma ${ }^{12}$.

Our case with 2 recurrences of multiple cardiac myxomas and acute tumoral pulmonary embolism is interesting because of the several uncommon findings discussed below.

From the clinical point of view, cardiac myxomas may be asymptomatic or manifest with symptoms of blood flow obstruction, with possible intermittent heart failure; severe constitutional symptoms, such as anorexia and weight loss; and in some cases, symptoms related to embolic phenomena ${ }^{6}$. In a study of 161 patients in Japan ${ }^{3}$, embolism was observed in only $9 \%$ of the patients. In our case, the patient 
experienced clinical manifestations of severe pulmonary embolism in her last hospitalization.

In regard to the location of the myxomatous formation, the left atrium is known to be its most common site. This was one of the initial locations in our case. However, since its first appearance, more than 1 cardiac cavity was involved, characterizing a multicentric disease, which may explain its higher chance of recurrence. According to McCarthy et al ${ }^{13}$ and Shinfeld et $\mathrm{al}^{14}$, among the 4 groups of patients in whom myxomas may recur (inadequate resection, multicentric tumors, familial type, and metastatic recurrence), those patients with multicentric tumors have an increased risk of recurrence-estimated in 33\% - as compared with sporadic myxomas, whose recurrence rate remains low, between $2 \%$ and $3 \%$.

Involvement of the right cardiac chambers, which does not exceed $20 \%$ of the cases of myxoma, may account for thromboembolism and pulmonary infarction, likewise in our case. These situations are neither very common nor frequently reported in the literature, and they may be confounded by other causes of pulmonary thromboembolism, mainly when the physical cardiac examination is normal $^{8}$.
Cardiac myxomas have been reported as part of a syndrome - Carney complex - characterized by pigmentation of the skin and mucosas, myxomatous tumors of the skin, heart, breast, and other organs, and a variety of endocrine tumors ${ }^{15}$. In our case, the patient had concomitant breast nodules, thyroid nodules, and adrenal involvement, which may constitute associated findings.

Analysis of these special types of myxomas shows a very close analogy between familial myxomas and the group at high risk for recurrence. Evidence suggests that recurring or multiple or familial myxomas represent the same entity ${ }^{16}$.

In conclusion, this rare case illustrates several less common points, such as multiple recurrences of cardiac myxomas, probably related to multicentric tumors; less common sites of tumor appearance, with involvement of the pulmonary artery causing thromboembolism; and the concomitant presence of breast and thyroid nodules, and adrenal alterations. As a diagnostic and preventive measure of recurrence of cardiac myxomas, we emphasize the importance of the periodic follow-up of the patient, with echocardiographic assessment, allowing early detection of a new recurrence and facilitating the management and planning of the surgical treatment.

\section{References}

1. Bjessmo S, Ivert T. Cardiac myxoma: 40 years' experience in 63 patients. Ann Thorac Surg 1997; 63: 697-700.

2. Manfroi WC, Zago AJ, Raudales JC, et al. Recorrência de mixoma cardíaco multicavitário. Arq Bras Cardiol 1995; 64: 405-7.

3. Endo A, Ohatahara A, Kinugawa T, Kinugawa T, et al. Characteristics of 161 patients with cardiac tumors diagnosed during 1993 and 1994 in Japan. Am J Cardiol 1997; 79: 1708-11.

4. Cruz JFM, Dias LB, Neto JOR, Oliveira AS. Mixoma gigante de átrio esquerdo. Arq Bras Cardiol 1998; 71: 717-8.

5. Chakfé N, Kretz JG, Valentin P, et al. Clinical presentation ando treatment options for mitral valve myxoma. Ann Thorac Surg 1997; 64: 872-7.

6. Takakura IT, Godoy MF, Soares MJ, et al. Mixoma atrial esquerdo com acidente vascular cerebral isquêmica em crianças. Arq Bras Cardiol 1998; 71: 135-7.

7. Peachell JL, Mullen JC, Bentley MJ, Taylor DA. Biatrial myxoma: A rare cardiac tumor. Ann Thorac Surg 1998; 65: 1768-9.

8. Jardine DL, Lamont DL. Right atrial myxoma mistaken for recurrent pulmonary thromboembolism. Heart 1997; 78: 512-14.
9. Redder GS, Khandheria BK, Seward JB, Tajik J. Transesophageal echocardiography and cardiac masses. Mayo Clin Proc 1991; 66: 1101-9.

10. Murphy DP, Glazier DB, Krause TJ. Mitral valve myxoma. Ann Thorac Surg 1997; 64: 1169-70.

11. Manfroi W, Ilha DO, Saadi J, et al. Mixoma de ventrículo direito: relato de um caso. Arq Bras Cardiol 1982; 38: 395-8

12. Castells E, Ferran V, Octavio de Toledo MC, et al. Cardiac myxomas: surgical treatment, long-term results and recurrence. J Cardiovasc Surg 1993; 34: 49-53.

13. McCarthy PM, Schaff HV, Winkler HZ, et al. Deoxyriboneucleic acid ploidy pattern of cardiac myxomas. Another predictor of biologically unusual myxomas. J Thorac Cardiovasc Surg 1989; 98: 1083-6.

14. Shinfeld A, Katsumata T, Westaby S. Recurrent cardiac myxoma: Seeding or multifocal disease? Ann Thorac Surg 1998; 66: 285-8.

15. Courcoutsakis NA, Chow CK, Shawker TH, et al. Syndrome of spotty skin pigmentation, myxomas, endocrine overactivity, and Shwannomas (Carney Complex): Breast imaging findings. Radiology 1997; 205: 221-7.

16. Duveau $\mathrm{D}, \mathrm{Baron} \mathrm{O}$, Jegou $\mathrm{B}$, et al. Multiple and recurrent cardiac myxomas. Is it a familial disease? Chirurgie 1993; 119: 357-61. 